\title{
CONTRIBUIÇÃO DA FIXAÇÃo SIMBIÓTICA DE NITROGÊNIO NA PRODUÇÃO DO GUANDU (Cajanus cajan (L.) Millsp).
}

\author{
M.J. VALARINI \\ Instituto de Zootecnia, C.P. 60, CEP: 13460-000 - Nova Odessa, SP \\ R. GODOY \\ CPPSE-EMBRAPA, C.P. 339, CEP: 13560-970 Säo Carlos, SP
}

\begin{abstract}
RESUMO: Experimento com guandu foi conduxido em casa-de-vegetação utilizando latossolo vermelho-amarelo variação Laras no Instituto de Zootecnia, Nova Odessa, SP, para avaliar parâmetros indiretos de fixação simbiotica de $\mathrm{N}_{2}$. As plantas utilizadas representam acessos de guandu obtidos no CPPSE-EMBRAPA, São Carlos, SP, selecionados para características agronomico-forrageiras. Matéria seca da parte aérea, matéria seca de nodulos, atividade de redução de acetileno, eficiência relativa e teor de nitrogênio total da parte aérea não diferiram significativamente $(P<0,05)$ entre os acessos de guandu inoculados com Bradyrhizobium spp e com diferentes características agronómicas. A inoculação possibilitou produção de massa verde com teor de nitrogênio (15 - 17\% proteína bruta) equivalente à fertilização de nitrogênio de $120 \mathrm{~kg}$ N/ha. Conclui-se que guandu pode estabelecer uma associação simbiótica capaz de fornecer mais de $\mathbf{9 0 \%}$ do nitrogénio necessário ao seu desenvolvimento vegetativo. Descritores: fixação de $\mathrm{N}_{2}$, nodulação, Bradyrhizobium, Cajanus cajan (L.) Millsp
\end{abstract}

\section{CONTRIBUTION OF SYMBIOTIC NITROGEN FIXATION ON PIGEONPEA YIELD (Cajanus cajan (L.) MFllsp)}

\begin{abstract}
ARSTRACT: Pigeon-pea accessions were grown in a yellow-red latossol var. Laras in a greenhouse at the Instituto de Zootecnia, Nova Odessa, SP, Brazil, to evaluate their $\mathrm{N}_{2}$ fixing characteristics. Shoot dry matter weight, mass of nodules, acetylene reduction activity, dry matter $\mathbf{N}$ content and relative efficiency were not significantly increased by the inoculation with recommended strains of Bradyrhizobium spp. However, inoculation made shoot weight and nitrogen content (15 - 17\% crude protein) comparable to the nitrogen fertilization level of $120 \mathrm{~kg} N / \mathrm{ha}$. It is concluded that the pigeon-pea can establish a Bradyrhizobium association able to provide more than $90 \%$ of nitrogen needed for its vegetative growth.
\end{abstract}

Keg Werds: nitrogen fixation, nodulation, Bradyrhizobium, Cajanus cajan (L.) Millsp

\section{INTRODUÇÃO}

Guandu (Cajanus cajan (L.) Millsp) é considerado leguminosa de importância agronômica, não somente pela produção de grãos de bom valor nutritivo ( $18-28 \%$ proteína) (KAHN \& RACHIE, 1972 citado por HERNANDEZ \& FOCHT, 1985), como também pela produção de biomassa. Devido sua adaptação à ampla gama de solos e climas, o guandu pode representar uma alternativa viável como leguminosa forrageira tropical (HERNANDEZ \& FOCHT, 1985; OGATA et al., 1988). Sendo o nitrogênio um dos elementos nutricionais freqüentemente limitantes em solos tropicais e a cultura do guandu normalmente pouco fertilizada, a fixação biológica de $\mathrm{N}_{2}$ é de considerável importância nessas condições. Devido à presença de populações nativas de bradyrizobio em tais solos (NORRIS, 1965), a necessidade da prática de inoculação nessas regiōes não é totalmente clara (HERNANDEZ \& FOCHT, 1985). Em solos com baixos teores de nitrogênio mineral, QUILT \& DALAL (1979) verificaram aumento na produção do guandu com a inoculação de Rhizobium. LA FAVRE \& FOCHT (1983) observaram que mais de $90 \%$ do nitrogênio da planta originou-se da fixação simbiótica de $\mathrm{N}_{2}$. POTH et al. (1986), estimaram através de diluição isotópica de ${ }^{15} \mathrm{~N}$, que a quantidade de $\mathrm{N}$ biologicamente fixada $e$ efetivamente incorporada ao solo, variou de 144 a $199 \mathrm{~kg} / \mathrm{ha}$, dependendo da estirpe de rizobio 
utilizada. Por outro lado, HERNANDEZ et al. (1982), relataram que o guandu não apresentou resposta à adição de nitrogênio nem à inoculação, em ensaio realizado em casa-de-vegetação.

$O$ presente trabalho objetivou avaliar a capacidade de nodulação e de fixação de $\mathrm{N}_{2}$, através de parâmetros indiretos, por diferentes acessos de guandu, inoculados com mistura de estirpes de Bradyrhizobium crescidas em casa-devegetação.

\section{MATERIAL E MÉTODOS}

\section{Estirpes de rizóbio: As estirpes de Bradyrhizobium} spp utilizadas, recomendadas para guandu, foram: CIAT 4983, originária do Panamá (P132) e obtida do Centro Internacional de Agricultura Tropical (CIAT), Cali/Colômbia; SEMIA 6157, originária da EMBRAPA, Brasil, e obtida da colação de culturas de Rhizobium do IPAGRO/MIRCEN, Rio Grande do Sul e IZ-Guandu, isolada e obtida do Instituto de Zootecnia, Nova Odessa, SP, Brasil. O inoculante foi preparado em meio TY (BERINGER, 1974) sob agitação à $28^{\circ} \mathrm{C}$. As plântulas foram inoculadas uma semana após o plantio, por ocasião do desbaste, com $1 \mathrm{ml}$ da cultura líquida, constituída pelas 3 estirpes, contendo cerca de $10^{8}$ células $/ \mathrm{ml}$, que foi adicionado ao colo da planta.

Acessos de Guandu: Foram utilizados acessos de guandu selecionadas em ensaio de avaliação agronômica realizado no CPPSE-EMBRAPA, São Carlos, SP, considerando-se os seguintes critérios de seleção: produção de matéria seca total e de folhas (pelo menos $20 \%$ superior à testemunha), retenção de folhas no inverno, (pelo menos $20 \%$ superior à testemunha), altura de plantas (pelo menos $10 \%$ inferior à testemunha), teor de nitrogênio na folha (pelo menos $10 \%$ superior à testemunha) e teor de tanino na folha (pelo menos $20 \%$ inferior à testemunha). Assim, os acessos selecionados e suas denominações foram: G6 (EPAMIG 1900); G10 (EPAMIG 1893); G17 (EPAMIG 1856); G18 (EPAMIG 1681); G19 (EPAMIG 1909); G24 (EPAMIG 1827); G27 (EPAMIG 1372); G45 (EPAMIG 1835); G48 (EPAMIG 1876); G58 (EEIT 85314 ANÃO); G59 (EEIT 85128) e G84 (Variedade Comercial utilizada como testemunha).

Ensaio Cultural: $O$ experimento foi conduzido em casa de vegetação em vasos com $3 \mathrm{~kg}$ de terra coletada na camada de 0 a $20 \mathrm{~cm}$ de profundidade de um Latossolo Vermelho-Amarelo var. Laras, cuja análise química apresentou os seguintes resultados: P: 18,7 ppm; M.O.: 1,84\%; pH: 5,12 em $\mathrm{CaCl}_{2}$; e, em meq $/ 100 \mathrm{~cm}^{3}$ de terra: $\mathrm{K}: 0,17$; Ca: 1,$67 ; \mathrm{Mg}: 1,3$; e H+Al: 1,60. Foi mantida uma planta por vaso. Os 12 tratamentos foram representados pelos diferentes acessos de guandu acima descritos. Os controles fertilizados com nitrogênio foram utilizados para cálculo da eficiência relativa. Os tratamentos foram arranjados em delineamento experimental inteiramente casualizado com 5 repetições. A terra dos vasos recebeu dose equivalente a $70 \mathrm{~kg} / \mathrm{ha}$ de cloreto de potássio (35 mg/kg de terra), $600 \mathrm{~kg} / \mathrm{ha}$ de superfosfato simples $(300 \mathrm{mg} / \mathrm{kg}$ de terra $)$ e o tratamento nitrogenado, $120 \mathrm{~kg}$ de $\mathrm{N} / \mathrm{ha}$ na forma de $\mathrm{KNO}_{3}$ (462 $\mathrm{mg} \mathrm{KNO} / \mathrm{kg}$ de terra). As plantas foram colhidas 90 dias após o plantio.

Foram analisados os seguintes parâmetros: na parte aérea das plantas, matéria seca e teores de $\mathrm{N}$ total, proteina bruta e composição mineral em $\mathrm{K}, \mathrm{Ca}, \mathrm{Mg}, \mathrm{S}$ e $\mathrm{P}$ e nos nódulos, número, matéria seca e atividade redução de acetileno (ARA).

Os teores de $\mathrm{N}$ total e proteína bruta foram analisados de acordo com a metodologia descrita em AOAC (1970), enquanto que os minerais foram analisados de acordo com a metodologia descrita por MALAVOLTA et al. (1989). A atividade de redução de acetileno (ARA) foi feita 3 meses após o plantio. As raízes noduladas foram cortadas $e$ incubadas imediatamente por 30 minutos em frascos de 500 $\mathrm{ml}$ com $10 \%$ de $\mathrm{C}_{2} \mathrm{H}_{2}$. Amostras da fase gasosa foram então retiradas e analisadas em cromatógrafo à gás. As taxas de redução de acetileno foram calculadas segundo HARDY et al. (1973).

\section{RESULTADOS E DISCUSSÃo}

Embora o guandu tenha mostrado resposta à inoculação por estirpes recomendadas de Bradyrhizobium, como se observa pelas eficiências relativas, não foram observadas diferenças significativas nos parâmetros de produção entre acessos de guandu com diferentes características agronômicas (TABELA 1).

SAXENA et al. (1975) observaram nodulação significativamente maior em plantas inoculadas de guandu, sendo que a calagem possibilitou resposta máxima à nodulação. 
TABELA 1 - Parâmetros de produção e avaliação de fixação de $\mathrm{N}_{2}$ em acessos de guandu inoculados e crescidos em condições de casa-de-vegetação aos 90 dias. Médias de 5 repetições.

\begin{tabular}{cccccc}
\hline \hline $\begin{array}{c}\text { Acessos } \\
\text { C. cajan }\end{array}$ & $\begin{array}{c}\text { Mat.Seca p.aérea } \\
\text { (g/planta) }\end{array}$ & $\begin{array}{c}\text { Mat.Seca } \\
\text { nódulo }(\mathrm{mg} / \mathrm{pl} .)\end{array}$ & $\begin{array}{c}\text { N Total } \\
(\%)\end{array}$ & $\begin{array}{c}\text { ARA }(\mu \mathrm{mol} \\
\left.\mathrm{C}_{2} \mathrm{H}_{4} / \mathrm{pl} . \mathrm{h}\right)\end{array}$ & $\begin{array}{c}\text { Ef.Rel.(1) } \\
(\%)\end{array}$ \\
\hline G6 & 5,07 & 138,00 & 2,52 & 5,64 & $74,76 \mathrm{ab}$ \\
G10 & 4,78 & 180,00 & 2,60 & 8,25 & $86,04 \mathrm{a}$ \\
G17 & 4,47 & 110,00 & 2,63 & 3,72 & $82,12 \mathrm{ab}$ \\
G18 & 4,96 & 114,00 & 2,73 & 6,80 & $87,45 \mathrm{a}$ \\
G19 & 5,18 & 170,00 & 2,67 & 6,80 & $84,72 \mathrm{ab}$ \\
G24 & 4,40 & 96,00 & 2,51 & 4,46 & $84,01 \mathrm{ab}$ \\
G27 & 5,76 & 114,00 & 2,53 & 4,40 & $67,75 \mathrm{~b}$ \\
G45 & 4,92 & 122,00 & 2,72 & 5,92 & $81,72 \mathrm{ab}$ \\
G48 & 4,41 & 142,00 & 2,68 & 5,10 & $73,81 \mathrm{ab}$ \\
G58 & 3,49 & 158,00 & 2,62 & 5,05 & $85,95 \mathrm{a}$ \\
G59 & 5,90 & 164,00 & 2,60 & 7,21 & $81,90 \mathrm{ab}$ \\
G84 & 6,11 & 132,00 & 2,52 & 3,74 & $75,83 \mathrm{ab}$ \\
\hline CV(\%) & 30,37 & 43,81 & 9,86 & 72,51 & $10,38(2)$ \\
d.m.s. & 3,27 & 0,13 & 0,56 & 8,82 & $18,18(2)$ \\
\hline \hline
\end{tabular}

C.V. Coef. de variação; valores seguidos de letras distintas diferem significativamente pelo teste de TUKEY $(\mathrm{P}<0,05)$.

(1) Ef. Rel. = (média $\mathrm{N}$ total planta inoculada: média $\mathrm{N}$ total planta com $\mathrm{N}$ ) $\times 100$.

(2) Estimativa de dados transformados para arco seno raiz quadrada da porcentagem.

Efeitos de calagem e pH do solo sobre a fixação de $\mathrm{N}_{2}$ em guandu foram discutidos por DALAL \& QUILT (1977) HERNANDEZ \& FOCHT (1985); OGATA et al. (1988). DUDEJA \& KHURANA (1989) verificaram que o potencial de fixação de $\mathrm{N}_{2}$ do guandu pode ser limitado à pobre nodulação, e não necessariamente à baixa eficiência. Plantas de guandu noduladas podem conter mais de $90 \%$ de nitrogênio advindo da fixação simbiótica de N2 (LA FAVRE \& FOCHT, 19984). Estima-se que o nitrogênio biologicamente fixado em guandu pode atingir até cerca de 200 $\mathrm{kg} / \mathrm{ha}$, dependendo da estirpe de rizóbio inoculada (POTH et al., 1986). Dos valores de Eficiências Relativas (E.R.) (TABELA 1), verifica-se que a fixação de $\mathrm{N}_{2}$ foi praticamente equivalente à adubação nitrogenada de $120 \mathrm{~kg} \mathrm{~N} / \mathrm{ha}$. Em geral, as ERs foram superiores a $90 \%$, com exceção a G27, que apresentou ER inferior a G10, G18 e G58. Esses resultados sugerem que o guandu pode depender da fixação simbiótıca para suprir o nitrogênio grande parte de seu desenvolvimento vegetativo, principalmente em condições de solos de baixa fertilidade sem adubação nitrogenada. $O$ teor de nitrogênio total da matéria seca variou de
2,5 a $2,8 \%$, resultando em um conteúdo de proteína bruta de 15 a $17 \%$ (TABELAS 1 e 2). Os acessos de guandu não mostraram diferenças significativas na capacidade de fixação de $\mathbf{N}_{2}$.

A TABELA 2 traz a composição dos principais minerais e proteína bruta (PB) da matéria seca dos diferentes acessos de guandu utilizados.

Através da estimativa do coeficiente de correlação de Pearson (SNEDECOR \& COCHRAN 1967), verificou-se que os teores de enxofre. fósforo, nitrogênio, bem como, peso seco dos nódulos e matéria seca da parte aérea correlacionaram-se positiva e significativamente $(P<0,01)$ à atividade de redução de acetileno (ARA), segundo os valores 0,$41 ; 0,54 ; 0,48 ; 0,56$ e 0,38 , respectivamente. Neste contexto, LA FAVRE \& FOCHT (1985) verificaram correlação entre teor de nitrogênio da parte aérea com peso seco de nódulos.

Os nódulos produzidos apresentaram de 1 a $9 \mathrm{~mm}$ de comprimento, com forma alongada $\mathrm{e}$ algumas vezes de extremidades bifurcadas. Mostraram-se de coloração interior rosa intensa, sugerindo a presença de nódulos ativos tal como evidenciado pela atividade de redução de acetileno das raizes noduladas. 
TABELA 2 - Composição mineral e conteúdo de proteína bruta de acessos de Cajanus cajan desenvolvidos em casa-de-vegetação $e$ inoculados com Bradyrhizobium spp. Médias de 5 repetições aos 90 dias após plantio.

\begin{tabular}{|c|c|c|c|c|c|c|}
\hline Acessos & $\mathrm{K}(\%)$ & $\mathrm{Ca}(\%)$ & $\operatorname{Mg}(\%)$ & $S(\%)$ & $\mathrm{P}(\%)$ & $\mathrm{PB}(\%)$ \\
\hline G6 & 0,91 & $0,53 \mathrm{ab}$ & 0,18 & 0,10 & 0,10 & 15,72 \\
\hline G10 & 1,10 & $0,50 \mathrm{ab}$ & 0,21 & 0,11 & 0,11 & 16,30 \\
\hline G17 & 1,06 & $0,72 \mathrm{a}$ & 0,17 & 0,11 & 0,09 & 16,41 \\
\hline G18 & 1,06 & $0,46 \mathrm{~b}$ & 0,24 & 0,11 & 0,10 & 17,05 \\
\hline G19 & 1,03 & $0,55 \mathrm{ab}$ & 0,23 & 0,12 & 0,10 & 16,72 \\
\hline G24 & 0,99 & $0,60 a b$ & 0,20 & 0,09 & 0,11 & 15,71 \\
\hline G27 & 0,97 & $0,50 a b$ & 0,22 & 0,09 & 0,11 & 15,81 \\
\hline G45 & 0,97 & $0,59 a b$ & 0,23 & 0,11 & 0,11 & 17,01 \\
\hline G48 & 1,08 & $0,64 a b$ & 0,16 & 0,10 & 0,10 & 16,74 \\
\hline G58 & 1,02 & $0,51 \mathrm{ab}$ & 0,21 & 0,11 & 0,11 & 16,40 \\
\hline G59 & 0,97 & $0,60 a b$ & 0,23 & 0,09 & 0,11 & 16,25 \\
\hline G84 & 1,04 & $0,60 \mathrm{ab}$ & 0,19 & 0,10 & 0,09 & 15,78 \\
\hline $\mathrm{CV}(\%)$ & 13,35 & 19,02 & 38,96 & 15,68 & 15,15 & 9,87 \\
\hline d.m.s. & 0,30 & 0,23 & 0,17 & 0,04 & 0,03 & 3,50 \\
\hline
\end{tabular}

C.V., Coef. de variação; valores seguidos de letras diferentes diferem significativamente pelo teste de TUKEY $(P<0,05)$.

Devido à ocorrência de populações autóctones de rizóbio "cow pea" nos solos tropicais, há que se analisar a necessidade de inoculação de leguminosas em tais solos. Contudo, dada a importância do incremento de $\mathrm{N}$ no sistema solo-planta, do processo simbiótico, principalmente em solos pobres, considerável atenção deve ser dispensada à prática de inoculação dos mesmos.

Neste trabalho, o guandu mostrou habilidade em estabelecer uma associação simbiótica capaz de suprir grande parte do nitrogênio necessário ao bom desenvolvimento vegetativo.

\section{CONCLUSÕES}

- Diferenças agronômicas entre variedades de guandu podem não apresentar diferentes respostas à nodulação e fixação de $\mathrm{N}_{2}$.

- O guandu pode estabelecer associação simbiótica com Bradyrhizobium capaz de suprir mais de $\mathbf{9 0 \%}$ do nitrogênio necessário ao seu desenvolvimento.

- O conteúdo de proteína bruta da matéria seca de guandu pode atingir níveis superiores a $15 \%$.

\section{REFERENCIAS BIBLIOGRÁFICAS}

ASSOCIATION OF OFFICIAL AGRICULTURAL CHEMISTS, Official methods of analysis, 12.ed. Washington: 1970. p.456-473.

BERINGER, J.E. A factor transfer in Rhizobium leguminosarum. Joumal of General Microbiology New York, v.84, p.188-198, 1974.

DALAL, C; QUILT, P. Effect of N, P, liming and Mo on the nutrition and grain yield of pigeon peas. Agronomy Journal, Madison, v.69, p.854-857, 1977.

DUDEJA, S.S.; KHURANA, A.L. Persistence of Bradyrhizobium sp (Cajanus) in a Sandy Loam. Soil Biology and Biochemistry, Oklahoma, v.21, p.709713, 1989.

HARDY, R.W.F.; BURNS, R.C.; HOLSTEN, R.D. Applications of the acetylene reduction assay for measurement of nitrogen fixation. Soil Biology and Biochemistry, Oklahoma, v.5, p.47-81, 1973.

HERNANDEZ, B.S.; FOCHT, D.D. Effects of phosphorus, calcium and Hup- and Hup + rizobia on pigeon pea yields in an infertilite tropical soil. Agronomy Journal, Madison, v.77, p.867-871, 1985. 


\section{CONTRIBUIÇÃO DA FIXAÇÃo SIMBIÓTICA DE NITROGÊNIO NA PRODUÇÃO DO GUANDU ...}

HERNANDEZ, B.C.; MENDEZ-LAY, H.M.; FOCHT, D.D. Nitrogen and phosphorus requirements for the growth and nodulation of Cajanus cajan in Panamanian soils. In: GRAHAM, P.H., HARRIS, S.C. (Eds.) Biological nitrogen fixation technology for tropical agriculture. Cali, Colombia: CIAT, s.d. p.167-171.

LA FAVRE, J.S.; FOCHT, D.D. Comparison of $\mathbf{N}_{2}$ fixation and yields in Cajanus cajan between hydrogenase-positive and hydrogenase negative rhizobia by "in situ" acetylene reduction assays and direct ${ }^{15} \mathrm{~N}$ partitioning. Plant Physiolpgy, Madison, v.72, p.971-977, 1982.

LA FAVRE, J.S.; FOCHT, D.D. Nitrogen fixation and hydrogen evolution by the pigeon-pea-Rhizobium symbiosis. Tropical Agriculture, Trinidad, v.62, p.285-288, 1985 .

MALAVOLTA, E.; VITTI, G.C.; OLIVEIRA, S.A. de. Avaliação do Estado Nutricional das Plantas; Princípios e Aplicações. Piracicaba: Associação Brasileira para Pesquisa da Potassa e do Fosfato, 1989. 210p.

NORRIS, D.O. Acid prodution by Rhizobium: a unifying concept. Plant Soil, Madison, v.22, p.143-166, 1965.
OGATA, S.; AGU-GYAMFI, J.; FUJTTA, K. Effect of phosphorus and $\mathrm{pH}$ on dry matter production, dinitrogen fixation and critical phosphorus concentration in pigeon pea (Cajanus cajan (L.) Millsp). Soil Science and Plant Nutrition, v.34. Madison, p.55-64, 1988.

POTH, M.; LA FAVRE, J.S.; FOCHT, D.D. Quantification by direct ${ }^{15} \mathrm{~N}$ dilution of fixed $\mathrm{N} 2$ incorporation into soil by Cajanus cajan (Pigeon pea). Soil Biology and Biochemistry, Oklahoma, v.18, p.125-127, 1986.

QUILT, P.; DALAL, R.C. Effect of soil mineral N levels and inoculation on nodulation, nitrogenase activity and grain yield of pigeon pea. Agronomy Journal, Madison, v.71, p.450-452, 1979.

SAXENA, M.C.; TILAK, K.V.B.B.R.; YADAV, D.S. Response of pigeon pea to inoculation and pelleting. Indian Journal of Agronomy, New Delhi, v.20, p.321-324, 1975 .

SNEDECOR, J.W.; COCHRAN, W.G. Statistical Methods. $6^{\mathbf{2}}$ ed. The Iowa State University Press, Ames, Iowa, U.S.A. 593p. 1967.

Recebido para publicaçāo em 29.03.94

Aceito para publicação em 01.08 .94 